\title{
1 Title: Nutraceutical profiles of apricots (Prunus armeniaca L.) as a source of fruit quality traits for
}

\section{2 breeding}

3

4 Running title: Nutraceutical properties of apricot fruits

5

6 Helena Gómez-Martínez ${ }^{1}$, Almudena Bermejo ${ }^{1}$, María Luisa Badenes ${ }^{1}$ and Elena Zuriaga ${ }^{1}$ *

$7 \quad$ Citriculture and Crop Production Center, Instituto Valenciano de Investigaciones Agrarias (IVIA), CV-315, Km. 10.7,

8 Moncada, 46113 Valencia, Spain

9 *Corresponding author: garcia_zur@gva.es

10

11 Keywords

12 Sucrose, glucose, fructose, ascorbic, citric, malic, succinic, fumaric, breeding 


\section{Summary}

14 In a social context of increasingly concern about healthy diets, the development of new varieties with enhanced content

15 in nutraceutical compounds is an increasingly important objective of the fruit breeding programs currently developed.

16 In this sense, apricot is a fruit crop very appreciated by consumers due to its organoleptic characteristics, but also plays

17 an important role in human nutrition due to its contain of phytocompounds as sugars, organic acids, vitamins and

18 polyphenols. In this work, new selections from the apricot breeding program carried out at the Instituto Valenciano de

19 Investigaciones Agrarias (IVIA) and traditional varieties have been analysed aimed at identifying sources of genetic

20 variation for fruit quality. For this purpose, sugar content, organic acids and ascorbic acid were studied during two crop

21 years. Results revealed sucrose and glucose as the major sugars, malic and citric acid as the main organic acids, and

22 diverse ascorbic acid content among the cultivars studied. Results obtained pointed some accessions as potential sources

23 to increase fruit quality. In addition, the study showed that apricot peel is an excellent source of nutraceutical

24 compounds. Moreover, this study opens up new possibilities for future work to study the genetic control of these traits

25 in apricot.

\section{1. Introduction}

28 The increasing demand for safe, healthy and nutritious food by consumers, turn the internal quality of the fruit into one

29 of the main goals of the food industry. In this sense, plants and some fruits become a useful source of compounds with a

30 relevant role in improving health (Vieira da Silva et al., 2016; Slavin and Lloyd, 2012). In fact, plant extracts and their

31 bioactive compounds are used by the industry to produce functional food (Azmir et al., 2013). For this reason, those

32 fruits with high content of these compounds are of high interest for the industry. In this sense, nutraceutical profiles can

33 be used for promotion of fruit consumption as a natural functional food.

34 Apricot (Prunus armeniaca L.) is a stone fruit crop species with a large tradition in the Mediterranean basin countries.

35 World apricot production reached 3.84 million tonnes in 2018, being Turkey, Uzbekistan, Iran, Algeria, Italy and Spain

36 as main producers (http://www.fao.org/faostat/). Despite its wide geographical spread apricot has very specific

37 ecological requirements, so each region usually grows locally adapted cultivars. Significant breeding efforts have been

38 undertaken (Zhebentyayeva et al., 2012), leading to a rich diversity apricot germplasm in terms of fruit morphology,

39 harvest season or biotic and abiotic resistances. Apricots are consumed in multiple and diverse ways, including fresh or

40 processed fruits (as dried, canned, jam, juice or even liquors), and also used the apricot kernel oil for medicinal

41 purposes (Zhebentyayeva et al., 2012). Apricots are an important source of sugars, fiber, proteins, minerals and

42 vitamins (Sochor et al., 2010; Moustafa and Cross, 2019). However, pomological and nutraceutical properties depend

43 on varieties, cultivation systems, fruit storage conditions or developmental stages (Ruiz et al., 2005).

44 In terms of fruit consumption, organoleptic characteristics are one of the main factors for consumers decision.

45 Notwithstanding, nutraceutical compounds interact with each other and influence the quality properties making it 
46 difficult to handle. For instance, the flavour is provided by sucrose, malic acid and volatiles (Xi et al., 2016), being

47 sugar and organic acid balance relevant for sweetness. From them, fructose and sucrose are the prominent contributors

48 to sweetness, being the most important sensory quality for consumer satisfaction (Fan et al.,2017). Similar results have

49 been found in peach, whose sweetness depends on the overall sugar amount as well as in the specific relative amount of

50 each individual sugar (Kroger et al., 2006). Regarding the apricot nutraceutical profile, previous studies have also found

51 glucose and sucrose as the major sugars in both pulp and peel (Xi et al., 2016). Moreover, during the fruit ripening a

52 high number of molecular and metabolic changes occur that have a relevant effect in fruit properties (D'Ambrosio et

53 al., 2013; Karlova et al., 2014; Osorio et al., 2013; Seymour et al., 2013). For instance, organic acids increase during

54 the early stages of fruit development and decrease when fruits were full-ripped, being malic the most important organic

55 acid in apricot (Xi et al., 2016). Additionally, fruits and vegetables constitute the main source of ascorbate in the human

56 diet, so rising its content in highly consumed fruits would clearly have an impact on human nutrition (Fenech et al.,

57 2019). Moreover, ascorbate content has been also related with elevated stress tolerance (Fenech et al., 2019). In fact,

58 foliar application of ascorbic acid on peach trees resulted in improving the yield and fruit quality (Sajid et al., 2017).

59 Previous studies found that vitamin C content in apricot could reach up to $100 \mathrm{mg} / 100 \mathrm{~g}$ dry weight (Akin $e t$ al., 2008),

60 showing the potential of this species as a source of this vitamin.

61 In conclusion, apricot germplasm represent a diverse source of phytocompounds that can be exploited for breeding

62 purposes in order to develop new varieties with higher content of these nutraceutical compounds. The apricot breeding

63 program at the Instituto Valenciano de Investigaciones Agrarias (IVIA) has the purpose of obtaining new varieties, with

64 high fruit quality, resistant to the Plum Pox virus (PPV), self-compatibles and well-adapted to the Southern European

65 environment (Martínez-Calvo et al., 2009). PPV is the main limiting factor for apricot production worldwide, hence,

66 during the last decades, development of PPV resistant varieties has been the main objective of almost any apricot

67 breeding program. However, for this purpose, just some North American cultivars not well-adapted to Mediterranean

68 conditions were identified and used as resistance donors (Martínez-Gómez et al., 2000). This represents a challenge

69 especially in the current climate change scenario affecting the Mediterranean basin, with increasingly mild winters.

70 The objective of the present work is to assess the fruit quality characterization of 1 North-American, 3 Spanish

71 (Valencian Community) and 9 accessions from the IVIA's apricot breeding program aimed at identifying the most

72 convenient genotypes for increasing the fruit quality of apricot while keeping the adaptability to warm winters. In this

73 study we analyse sugars (sucrose, fructose, and glucose), ascorbic acid, and organic acids (citric, malic, succinic and

74 fumaric).

\section{2. Material and Methods}




\section{2.1. Plant Material}

77 Thirteen apricot genotypes were used, including 3 well-known cultivars from the Mediterranean Basin, 1 North-

78 American, and 9 selections from the IVIA's breeding program resistant to PPV (Table 1). All of them are kept at the

79 collection of the IVIA in Moncada (Valencia, Spain). Five fruits per tree were harvested at the ripening stage during 2

80 growing seasons (2016-2017). For each fruit, the peel was separated from the flesh with a peeler. A mix of 5 fruits (peel

81 or flesh, respectively) was frozen with liquid nitrogen and kept at $-80^{\circ} \mathrm{C}$ until processing. Peel samples were freeze-

82 dried and powdered. Tissue homogenization was carried out using a Polytrom 3100 (Kinematica AG, Switzerland) and

83 a vortex for the flesh and peel samples, respectively.

\section{2.2. Sample processing and HPLC analysis}

85 For sample processing, $1 \mathrm{~g}$ of flesh or $10-20 \mathrm{mg}$ of freeze-dried peels were mixed with $1.5 \mathrm{~mL}$ of $5 \%$ metaphosphoric

86 acid solution, , $1 \mathrm{~mL}$ of water of LC-MS grade and $1 \mathrm{~mL}$ of $0.1 \% \mathrm{H}_{2} \mathrm{SO}_{4}$ solution for ascorbic acid, sugars and organic

87 acids extraction, respectively. Then the sample was homogenized and centrifuged at $4^{\circ} \mathrm{C}$ for $20 \mathrm{~min}$ at $8.050 \mathrm{xg}$.

88 Compounds were identified on the bases of comparing their retention times, UV-vis spectra and mass spectrum data

89 with authentic standards obtained from Sigma-Aldrich using an external calibration curve. In addition, standards were

90 run daily with samples for validation. All the solvents used were of LC-MS grade. Three samples per cultivar were

91 analysed and all the samples were run in triplicate. The Empower 2 software (Waters, Spain) was used for data

92 processing.

\section{2.2.1. Ascorbic acid}

94 Total ascorbic acid was extracted according to the method previously described by Cano et al. (2011) adapted to a

95 microliter format (Sdiri et al., 2012) and using DL-dithiothreitol (DTT) as reducing reagent of dehydroascorbic acid to

96 ascorbic acid. After centrifugation, $1 \mathrm{~mL}$ of supernatant was mixed with $200 \mu \mathrm{L}$ of DTT $(20 \mathrm{mg} / \mathrm{mL})$ and maintained for

$972 \mathrm{~h}$ in the dark, then filtered through $0.45 \mu \mathrm{m}$ filter. It was analysed by HPLC-DAD in an Alliance liquid

98 chromatographic system (Waters, Barcelona, Spain) equipped with a 2695 separation module coupled to a 2996

99 photodiode array detector, and a reverse-phase $\mathrm{C}_{18}$ column Tracer Excel $5 \mu \mathrm{m} 120$ OSDB (250 mm x $\left.4.6 \mathrm{~mm}\right)$

100 (Teknokroma, Barcelona, Spain) with an isocratic mobile phase of methanol:0.6\% acetic acid (5:95) at a flow rate of 1

$101 \mathrm{~mL} / \mathrm{min}$, and injection volume was $5 \mu \mathrm{L}$. The quantification was performed at $245 \mathrm{~nm}$.

\section{2.2.2. Sugars}

103 Sucrose, glucose, and fructose were extracted as described by Sdiri et al. (2012). After centrifugation, samples were 104 filtered through a $0.45 \mu \mathrm{m}$ nylon filter and analysed by an HPLC system equipped with a Waters 515 HPLC pump, a 
105 Waters 2414 refractive index detector, a 5- $\mu \mathrm{m}$ Tracer Carbohydr column (250 mm x $4.5 \mathrm{~mm})$ (Teknokroma, Barcelona,

106 Spain), and a 20- $\mu \mathrm{L}$ loop Rheodyne injector were used for the sugar analysis. The mobile phase was composed of

107 acetonitrile and water $(75: 25)$ at a flow rate of $1.0 \mathrm{~mL} / \mathrm{min}$.

108 2.2.3. Organic acids

109 Citric, malic, succinic and fumaric acids were extracted as described by Sdiri et al. (2012). After centrifugation, the 110 supernatant was filtered through a $0.45 \mu \mathrm{m}$ filter, analysed by HPLC-DAD and confirmed by HPLC-MS under 111 electrospray ion negative conditions using a ZQ2000 mass detector. The sample temperature was $5^{\circ} \mathrm{C}$ and column 112 temperature was $35^{\circ} \mathrm{C}$. Capillary voltage was $3.0 \mathrm{kV}$, cone voltage was $23 \mathrm{~V}$, source temperature was $100^{\circ} \mathrm{C}$, 113 desolvation temperature was $200^{\circ} \mathrm{C}$ and desolvation gas flow was $400 \mathrm{~L} / \mathrm{h}$. Full data acquisition was performed by 114 scanning from 100 to 400 uma in the centroid mode. An ICSep ICE-COREGEL 87H3 column (Transgenomic, UK), an 115 ICSep ICE-COREGEL 87H guard kit, and an automatic injector were used for chromatographic separation. The solvent 116 system was an isocratic mobile phase of $0.1 \% \mathrm{H}_{2} \mathrm{SO}_{4}$ solution. The total run time was $20 \mathrm{~min}$ at $0.6 \mathrm{~mL} / \mathrm{min}$, and the 117 injection volume was $5 \mu \mathrm{L}$.

\section{$118 \quad 2.3$ Data analysis}

119 Data were analysed with R (R Core Team, 2012) using R-studio software (v.3.5.3) with stats, ggbiplot, readxl, graphics 120 and grDevices packages. Normality and homoscedasticity were checked using Shapiro-Wilk and Bartlett tests 121 respectively. Next, the non parametric Kruskal-Wallis test was used to make all samples comparisons. Correlation 122 coefficients among the variables were determined using the Spearman method. Principal component analysis (PCA), 123 using centered and scaled data, was conducted to visualize the relationships between accessions and variables.

\section{2.3.1. Sweetness Index (SI) and Total Sweetness Index (TSI)}

125 In order to determine the sweetness perception of fruits, both index were calculated according to Magwaza and Opara 126 (2015) following the equations:

$127 \mathrm{SI}=(1.00 \times[$ glucose $])+(2.30 \times[$ fructose $])+(1.35 \times[$ sucrose $])$

$128 \mathrm{TSI}=(1.00 \times[$ sucrose $])+(0.76 \times[$ glucose $])+(1.50 \times[$ fructose $])$ 
132 Fructose, glucose and sucrose content in peel and flesh showed significant differences $(\mathrm{p} \leq 0.05)$ between the accessions

133 analysed (Figure 1, Table S1). Regarding total sugar content in flesh, SEOP934 showed the highest value (12.34 g/100

$134 \mathrm{~g} \mathrm{FW})$ and HG9850 the lower one (5.75 g/100 g FW) (Figure 1A). In all cases sucrose was the predominant sugar,

135 ranging from 65.1 to $90.3 \%$ of the total. For each sugar, Tadeo showed the highest content of fructose $(0.48 \mathrm{~g} / 100 \mathrm{~g}$

$136 \mathrm{FW})$ and glucose (3.11 g/100 g FW), and SEOP934 showed the highest quantity of sucrose (10.3 g/100 g FW).

137 Regarding peel content, Kruskal-Wallist test showed an effect of the crop year over the fructose and glucose content,

138 but not over sucrose. According to the Spearman correlation analysis, seven significant correlations were observed

139 between the analysed sugars (Figure 2, Table S2). Mainly, fructose and glucose appear positively correlated between

140 tissues and also between years, while in peel fructose peel appeared negatively correlated with sucrose. The North

141 American Goldrich cultivar showed the lower total sugar content in 2016 (38.19 g/100 g DW) and the second lowest in

1422017 (23.68 g/100 g DW), mainly due to its low sucrose content (12.41 and $4.63 \mathrm{~g} / 100 \mathrm{~g} \mathrm{DW}$, respectively). In general,

143 the well-known cultivars from the Mediterranean Basin showed high sugar content and the accessions belonging to the

144 IVIA's breeding program showed an intermediate content between them and Goldrich. For each sugar, fructose ranged

145 between the 5.9-21.2 \% of total sugar measured, glucose between 19.7-45.6\% and sucrose between $35.5-71.1 \%$. As a

146 measure of sweetness, SI and TSI index were calculated (Table 2). According to these indexes, fruits with identical total

147 sugar content but with relatively more fructose or sucrose will taste sweeter. Overall, the Spanish cultivar Tadeo and 2

148 of the selections of the breeding program, HG9821 and SEOP934, were the sweetest according to these indexes.

149 Contrary, the selections Dama Rosa, GG979 and HG9850 have the lower values.

\section{3.2. Organic acids}

151 Significant differences among the apricot accessions were observed for citric, malic, succinic and fumaric acids content

152 (Figure 3, Table S3). Citric acid was the main organic acid in flesh in all cases, ranging from 50-80.1\%. Malic acid was

153 the second one except for Tadeo and SEOP934. Succinic represents between 7-22.93\% of the organic acids measured

154 and fumaric just between 0.07 and $0.17 \%$. Regarding total content in flesh, Dama Rosa showed the highest value (3.254

$155 \mathrm{~g} / 100 \mathrm{~g} \mathrm{FW})$ and Mitger the lower one (1.562 g/100 g FW) (Figure 3A). In this case, 8 significant correlations were

156 detected between organics (Figure 2), being the most notorious the negative correlation between succinic and citric

157 acids in peel. As in the case of sugars, an effect of crop year was observed in the fumaric acid peel content, with some

158 accessions showing higher values in 2017 (Figure 3B and 3C). Citric acid was the main organic acid in peel in all cases

159 except for Mitger ( 14.5\%\%) and Tadeo ( 20\%), which showed both years a higher content of malic acid (around 62\%

160 and 55\%, respectively), and Dama Rosa with 46.6\% in 2017. Succinic acid was the third one, except for Tadeo

161 ( 22.2\%), which showed more content than malic ( 20\%). Regarding the total content in peel, Goldrich showed the

162 highest values (20.7 and $31.7 \mathrm{~g} / 100 \mathrm{~g} \mathrm{DW})$, and Tadeo the lower ones (9.6 and $11.3 \mathrm{~g} / 100 \mathrm{gDW})$. 


\subsection{Ascorbic acid}

164 Results of ascorbic acid content in peel and flesh of the genotypes studied in the two crop years are in Figure 4 and

165 Table S4. Significant differences were found among genotypes and crop years (p-value $=0,0026)$. In flesh, values 166 ranged from $9.11 \mathrm{mg} / 100 \mathrm{~g} \mathrm{FW}$ (SEOP934) and $13.08 \mathrm{mg} / 100 \mathrm{~g} \mathrm{FW}$ (HG9821). Regarding peel content, Mitger and 167 HG9850 showed the highest values in 2016 (185.02 mg/100 g DW) and 2017 (192.82 mg/100 g DW) respectively. In 168 general, the accessions belonging to the IVIA's breeding program showed equal or higher content than Canino, which 169 showed the lowest value from the Mediterranean cultivars.

\section{3.4. Correlations and Principal Component Analysis}

171 As consumer preferences are highly influenced by the balance of sugar and organic acids content, relations between all 172 the analysed compounds were also studied (Figure 2). For instance, citric content in flesh was negatively correlated with 173 glucose and sucrose peel content, while in peel was negatively correlated with fructose and glucose flesh content. Malic 174 content in flesh was positively correlated with fructose content and negatively with sucrose, both in peel. Succinic 175 content in flesh was positively correlated with fructose and glucose. Finally, fumaric acid showed positive correlation 176 with ascorbic acid content.

177 In order to explore the variability observed in the accessions, the nutraceutical compounds analysed each year were 178 submitted to principal component analyses (PCA). As results with each independent data sets were quite similar, just 179 the PCA for 2017 is shown (Figure 5). First 3 principal components (PC1, PC2 and PC3) accounted for 78.1\% of the 180 total variance $(36.5 \%, 27.4 \%$ and $14.2 \%$, respectively). PC1 was positively correlated mainly with sucrose, fumaric acid 181 and ascorbic, while negatively with citric acid content. PC2 showed a positive correlation with citric acid and fructose, 182 and negatively with malic and succinic acids. The distribution of the accessions in the space of the 3 first components 183 showed one group of 6 accessions (Goldrich, GG979, GP9817, GG9310, Dama Taronja and Canino) situated at 184 negative values of PC1 and positive values of PC2. Rest of the accessions appear more distributed, and just two of them 185 were close to each other, HG9821 and HG9850, both descendants from the same cross.

\section{4. Discussion}

187 Traditionally, plant breeding goals have been focused on yield, stress resistance and external quality traits as appearance 188 and shelf-life. However, consumers are increasingly demanding high quality food. As an example, huge efforts are in 189 progress to recover the lost flavour in tomato cultivars (Tieman et al., 2017). Nowadays, internal quality traits have 190 been incorporated as objectives of almost any plant breeding program. The IVIA's apricot breeding program started in 1911993 and was initially focused on introgression of sharka resistance into locally grown cultivars (Martínez-Calvo et al., 192 2009). However, just a handful of North American apricot PPV resistant cultivars, adapted to cold-growing conditions, 
193 have been identified (Martínez-Gómez et al., 2000). Despite the crosses with those cultivars introduce also undesirable

194 traits, the hybrids obtained in the breeding program represent a good opportunity to incorporate new breeding goals and

195 to accelerate the development of new varieties better adapted to the Mediterranean basin conditions. In this sense, the

196 characterization of the nutraceutical properties of these germplasm collection allows to identify putative promising

197 accessions and to optimize the design of the future crosses. This study opens also future work to study the genetic

198 control of these traits in apricot. In this work, we analysed 13 accessions of the IVIA's collection in order to identify the

199 main source of variation for each phytocompound of interest: sugars (sucrose, fructose and glucose), organic acids

200 (citric, malic, succinic and fumaric) and vitamin C (ascorbic acid).

201 Apricot fruits are a good source of sugars, fiber, proteins, minerals and vitamins (Moustafa and Cross, 2019). Fruit taste

202 is highly dependent of the soluble solids content, which is the sum of sugars, acids and other minor components,

203 however sugars represent the most important proportion. As described in apricot and other Prunus species, sucrose,

204 glucose and fructose are the main sugars present in fruits (Bassi and Selli, 1990; Cirilli et al., 2016). For instance,

205 sucrose is the predominant sugar (40-85\%) in peach, followed by fructose and glucose in variable ratios (Cirilli et al.,

206 2016), similarly to our data presented here. According to Bae et al. (2014), the content of glucose and fructose was

207 higher than sucrose and sorbitol during fruit growth, these authors also pointed that sucrose increase as major sugar in

208 apricot and plum at the end of maturity, that is in accordance with our results. Consumer perception of sweetness

209 intensity depends on the overall sugar amount but also the specific profile (Cirilli et al., 2016). For this sweetness

210 estimation, the contribution of each carbohydrate is calculated, based on the fact that fructose and sucrose are sweeter

211 than glucose (Magwaza and Opara, 2015). Although comparisons with other previous works are complicated for this

212 type of traits, our values are similar to the ones obtained by Fan et al., (2017) analyzing northwest Chinese apricots.

213 According to our study, SEOP934, HG9821 and HG9850 could be good candidates as swetness source.

214 Organic acids also have an important role, with sugars, on apricot taste (Xi et al., 2016). All organic acids increase at

215 first and then fall throughout fruit development and ripening process (Xi et al., 2016). In agreement with the previous

216 studies already cited, malic and citric acids were predominant in the apricot genotypes analysed. In terms of taste

217 Dolenc-Sturm et al., (1999) pointed the stronger acidic taste of malic compared with citric acid, and conclude that the

218 optimal ratio between malic and citric acid is near the value of 0.8 . Interestingly, some accessions showed the

219 malic:citric ratio around this value, like Dama Rosa and HG9821, two accessions from the IVIA's breeding program,

220 and also Goldrich. Interestingly, the PPV resistant Dama Rosa cultivar has been already registered (Badenes et al.,

221 2018). Moreover, cultivars with high content in acids and low in sugars could be more appreciated, particularly those

222 with higher citric acid concentration (Dolenc-Sturm et al., 1999). Moreover, cultivars with high content of organic acids

223 could be also used as source of these compounds, as they can be used to provide acidity and sour flavour as additive in 
224 food products. For instance, malic acid is used for elaboration of sweets and fumaric acid is used as acidulant and

225 antioxidant in soft drinks and cake mixes (Moldes et al. 2017). In this sense, several of the selections studied could be

226 useful for the food-industry, like GG9310, GG979, and SEOP934 that appear as good candidates as they showed high

227 contents of total organics acids.

228 Finally, the ascorbic acid is one of the most important vitamin in fruits (Lee and Kader, 2000), because of its protective

229 activity as antioxidant (Rice-Evans et al., 1997). We found significant differences in ascorbic acid contents between

230 crop years and among genotypes. Our results are in agreement with others studies on apricot varieties (Akin et al.,

231 2008; Gündogdu et al., 2013), with values ranging from 98.70 to $192.82 \mathrm{mg} / 100 \mathrm{~g}$ DW among varieties and crop year.

232 HG9850 and HM964 could be suggested as promising cultivars for ascorbic acid content improving due to their high

233 content and stable behaviour in both years.

234 The increasing demand of healthy products has raised the need of using alternative supplements and additives in food

235 and, fruit nutraceutical compounds can be a good choice since they can be extracted from natural sources and can

236 provide extra health benefits (Moldes et al., 2017). Our results suggest that apricot peel is a good source of sugars,

237 vitamins and organic acids, being an interesting provider of nutraceutical compounds. Our results are in agreement with

238 other authors that pointed the apricot peel as an extraordinary source of nutraceutical compounds and an optimum tissue

239 for studying mechanisms of flavour quality formation in fruit (Xi et al., 2016; Voo et al., 2012). Similar results were

240 found in previous apricot studies (Ruiz et al., 2005) and other fruits species like pear (Li et al., 2014) or peach

241 (Campbell et al., 2013).

\section{4. Conclusions}

243 A set of selections and genitors from the IVIA's apricot breeding collection has been characterized from a nutraceutical

244 point of view and the main sources of variation of the group of genotypes have been identified, which can be considered

245 as a previous step for further breeding. Our results confirmed the diversity among the set of apricot studied regarding to

246 sugars, organic acids and ascorbic acid content.

\section{Acknowledgments}

249 This study was funded by the Instituto Nacional de Investigación y Tecnología Agraria y Alimentaria (INIA)-FEDER

250 (RTA2017-00011-C03-01) and the Generalitat Valenciana (GV/2016/189). HGM was funded by a fellowship from

251 INIA.

\section{Declaration of Competing Interest}


253 The authors declare no conflict of interest. The funders had no role in the design of the study; in the collection,

254 analyses, or interpretation of data; in the writing of the manuscript, or in the decision to publish the results.

\section{Author contributions}

256 Helena Gómez-Martínez: Data curation, Formal analysis, Writing - review \& editing; Almudena Bermejo: Data

257 curation, Methodology; María Luisa Badenes: Conceptualization, Funding acquisition, Supervision, Writing - review \&

258 editing; Elena Zuriaga: Conceptualization, Data curation, Formal analysis, Funding acquisition, Writing - original draft,

259 Writing - review \& editing

260

261

262

263 


\section{Table 1: Apricot accessions analysed}

\begin{tabular}{lllcc}
\hline & & \multicolumn{2}{c}{ Harvest date } \\
\hline Genotype & Pedigree & Country & $\mathbf{2 0 1 6}$ & $\mathbf{2 0 1 7}$ \\
\hline Goldrich & Sunglo x Perfection & USA & June 22nd & 9th June \\
Canino & Unknown & Spain (Valencia) & June 3rd & 31st May \\
Mitger & Unknown & Spain (Valencia) & June 3rd & 25th May \\
Tadeo & Unknown & Spain (Valencia) & June 15th & 9th June \\
Dama Rosa & Goldrich x Ginesta & Spain (IVIA) & June 6th & 9th June \\
Dama Taronja & Goldrich x Katy & Spain (IVIA) & June 10th & 9th June \\
GG9310 & Goldrich x Ginesta & Spain (IVIA) & June 6th & 9th June \\
GG979 & Goldrich x Ginesta & Spain (IVIA) & June 13th & 9th June \\
GP9817 & Goldrich x Palau & Spain (IVIA) & June 13th & 9th June \\
HG9821 & Harcot x Ginesta & Spain (IVIA) & June 8th & 25th June \\
HG9850 & Harcot x Ginesta & Spain (IVIA) & June 3rd & 25th June \\
HM964 & Harcot x Mitger & Spain (IVIA) & June 1st & 2nd June \\
SEOP934 & SEO x Palau & Spain (IVIA) & June 8th & 2nd June \\
\hline
\end{tabular}


bioRxiv preprint doi: https://doi org/10 1101/20201130 403527: this version posted December 1 2020. The copvriaht holder for this preprint (which was not certified by peer review) is the author/funder, who has granted bioRxiv a license to display the preprint in perpetuity. It is made available under aCC-BY-NC-ND 4.0 International license.

267 Table 2: Sweetness estimation, SI and TSI were calculated according to Magwaza and Opara (2015).

\section{SI $\quad$ TSI}

\begin{tabular}{lcccccc}
\hline Genotype & Flesh_2016 & Peel_2016 & Peel_2017 & Flesh_2016 & Peel_2016 & Peel_2017 \\
\hline Goldrich & 9,33 & 51,67 & 30,74 & 6,89 & 37,20 & 21,68 \\
Canino & 10,43 & 63,91 & 63,45 & 7,72 & 47,00 & 46,34 \\
Mitger & 8,50 & 66,22 & 81,48 & 6,25 & 48,22 & 59,60 \\
Tadeo & 13,88 & 70,66 & 63,02 & 10,24 & 51,79 & 45,63 \\
Dama Rosa & 14,40 & 55,04 & 23,08 & 10,66 & 40,15 & 16,66 \\
Dama Taronja & 12,04 & 52,27 & 44,83 & 8,90 & 38,13 & 32,17 \\
GG9310 & 10,56 & 54,46 & 46,20 & 7,81 & 39,70 & 33,27 \\
GG979 & 7,56 & 50,54 & 44,51 & 5,60 & 36,91 & 31,82 \\
GP9817 & 9,98 & 59,19 & 52,29 & 7,38 & 43,24 & 37,61 \\
HG9821 & 10,74 & 62,78 & 92,30 & 7,93 & 45,73 & 67,37 \\
HG9850 & 7,55 & 61,78 & 66,43 & 5,58 & 45,34 & 48,50 \\
HM964 & 8,82 & 54,53 & 76,46 & 6,51 & 39,79 & 56,03 \\
SEOP934 & 16,30 & 63,58 & 43,30 & 12,05 & 46,60 & 31,20 \\
\hline
\end{tabular}


bioRxiv preprint doi: https://doi.org/10.1101/20201130.403527. this version posted December 1,2020. The copyright holder for this preprint (which was not certified by peer review) is the author/funder, who has granted bioRxiv a license to display the preprint in perpetuity. It is made available under aCC-BY-NC-ND 4.0 International license.

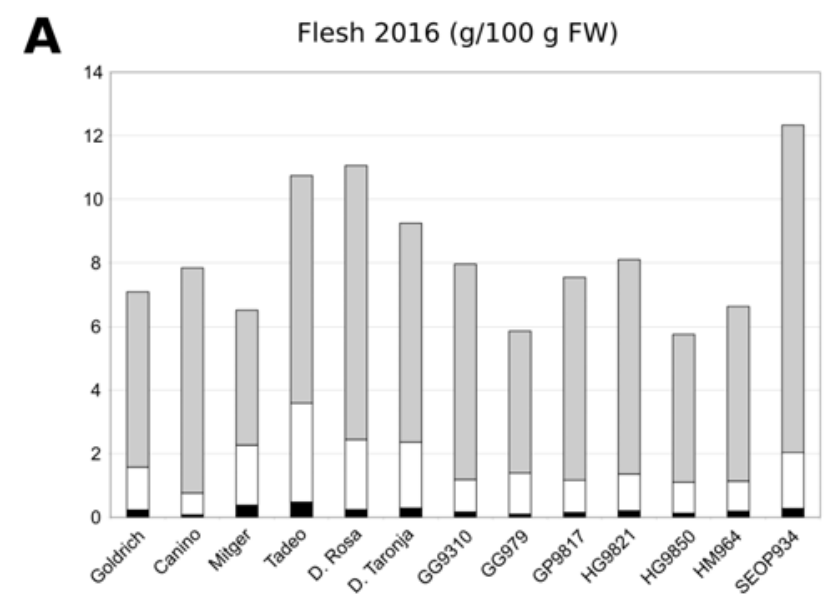

B

Peel 2016 (g(100 g DW)

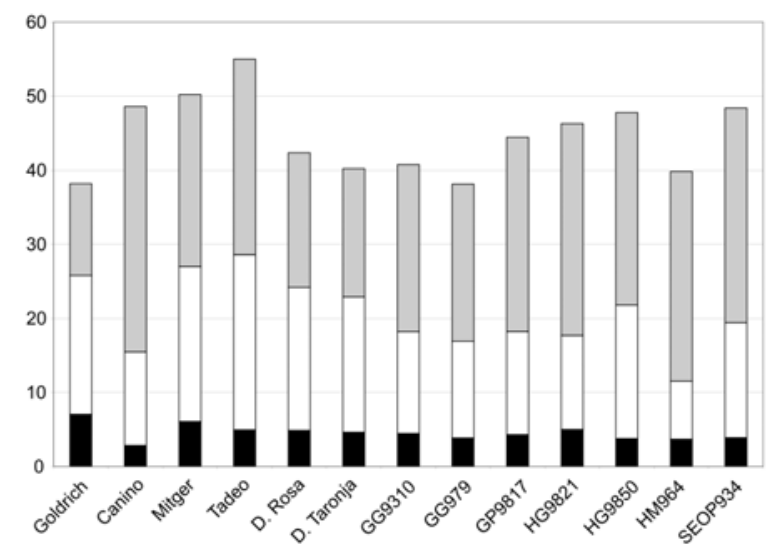

C

Peel 2017 (g/100 g DW)

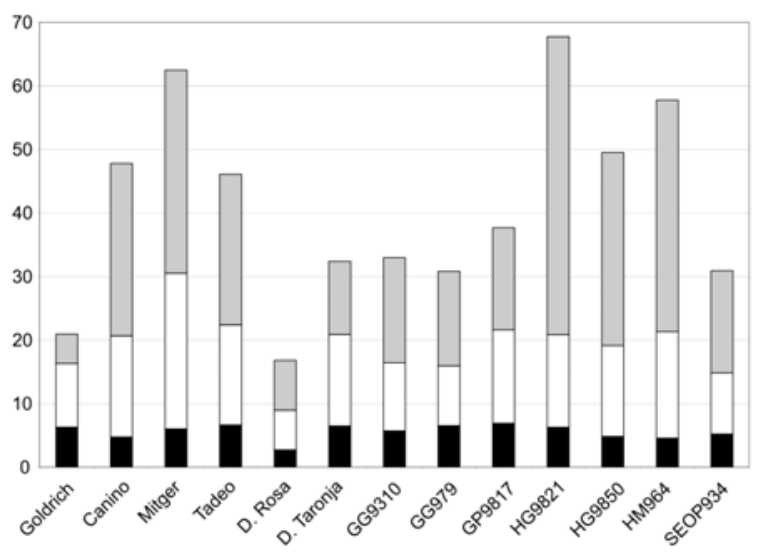

271

-Fructose $\square$ Glucose $\square$ Sucrose

272 Figure 1: Profiles of sugar content in flesh (g/100 g fresh weight $(\mathrm{FW}))$ and peel $(\mathrm{g} / 100 \mathrm{~g}$ dry weight $(\mathrm{DW}))$

273 during 2016 and 2017. 


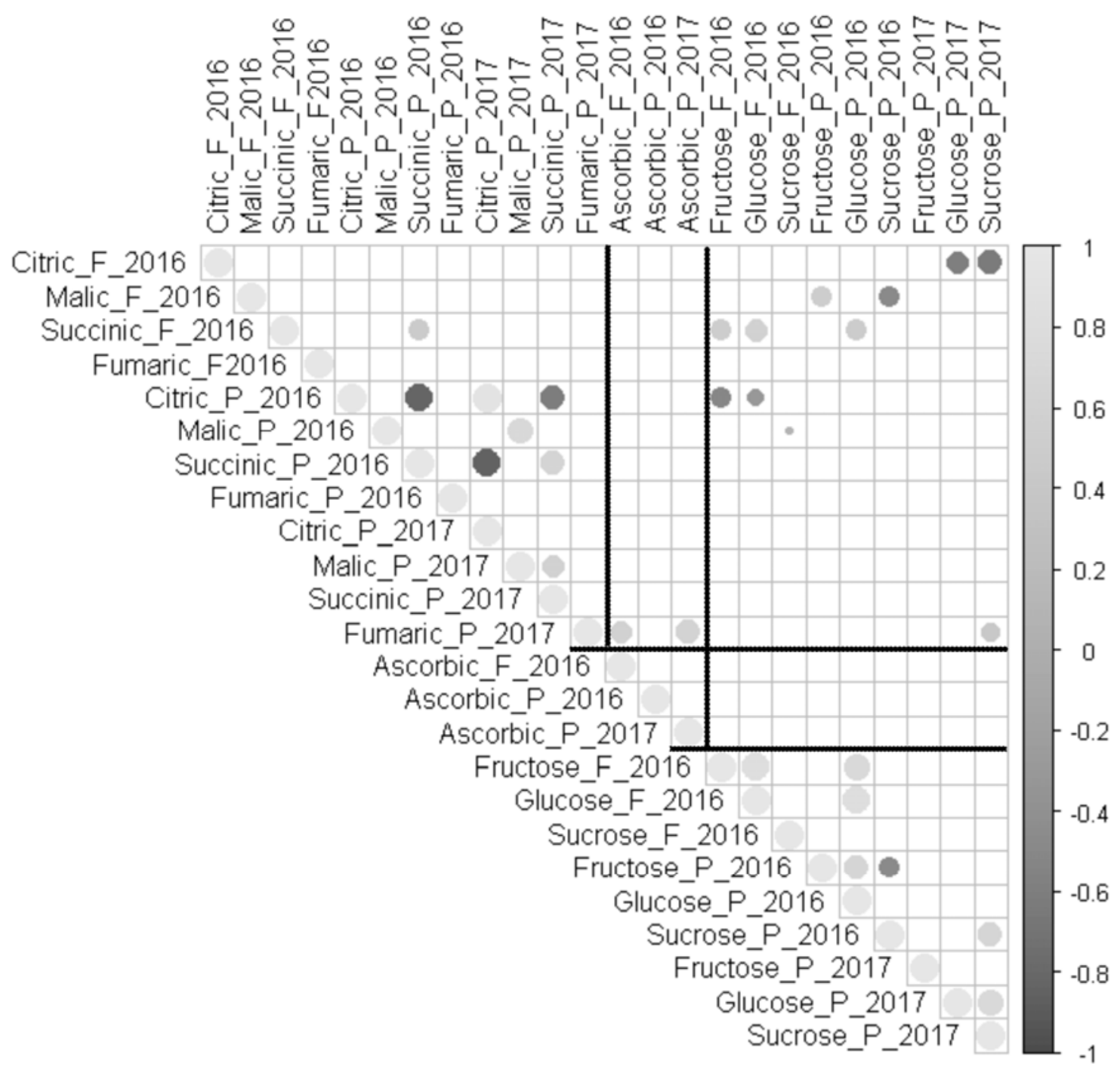

277 Figure 2: Significant correlations between variables analysed $(\boldsymbol{\alpha}=\mathbf{0 , 0 5})$ 
bioRxiv preprint doi: https://doi.org/10.1101/2020.11.30.403527; this version posted December 1, 2020. The copyright holder for this preprint (which was not certified by peer review) is the author/funder, who has granted bioRxiv a license to display the preprint in perpetuity. It is made available under aCC-BY-NC-ND 4.0 International license.

A

Flesh 2016 (g/100 g FW)
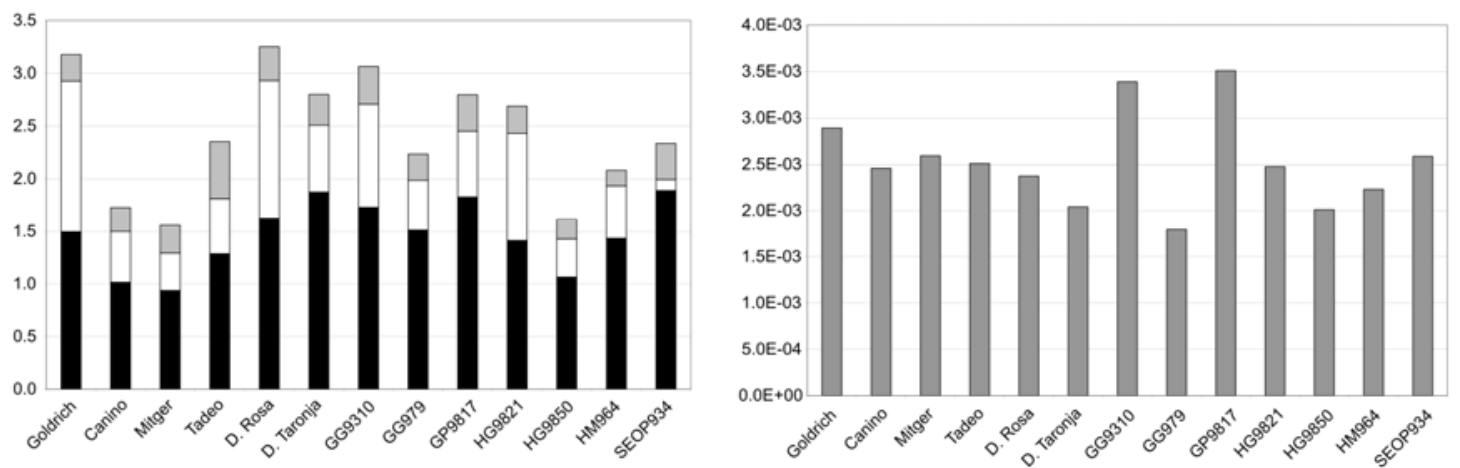

B

Peel 2016 (g/100 g DW)
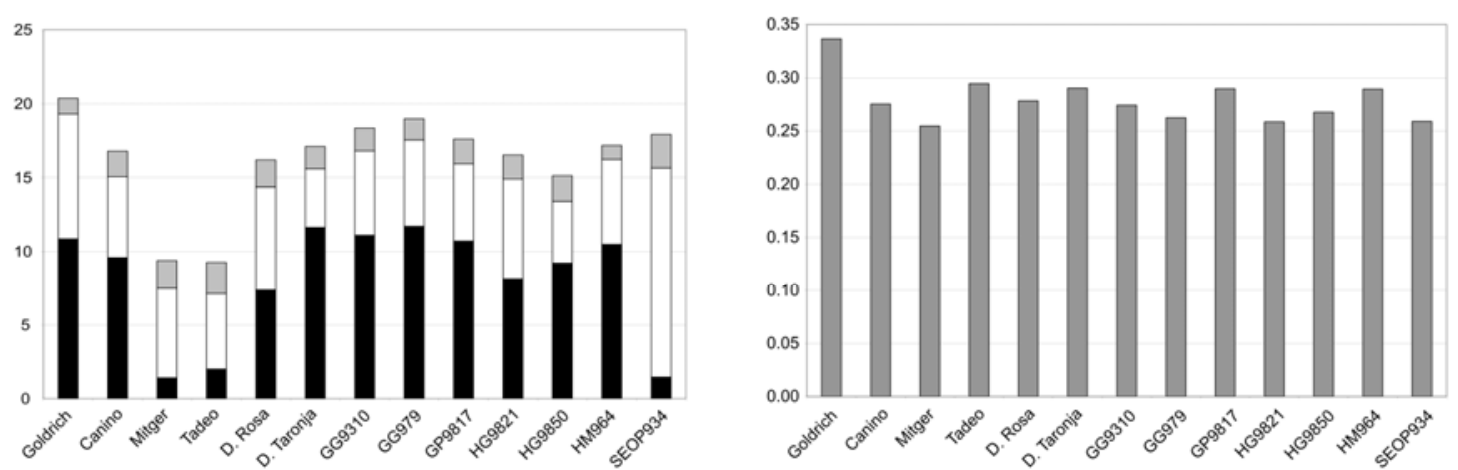

C

Peel 2017 (g/100 g DW)

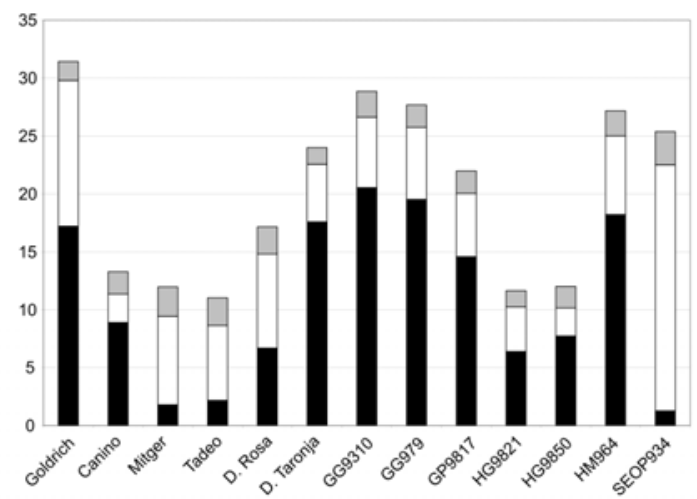

- Citric $\square$ Malic $\square$ Succinic

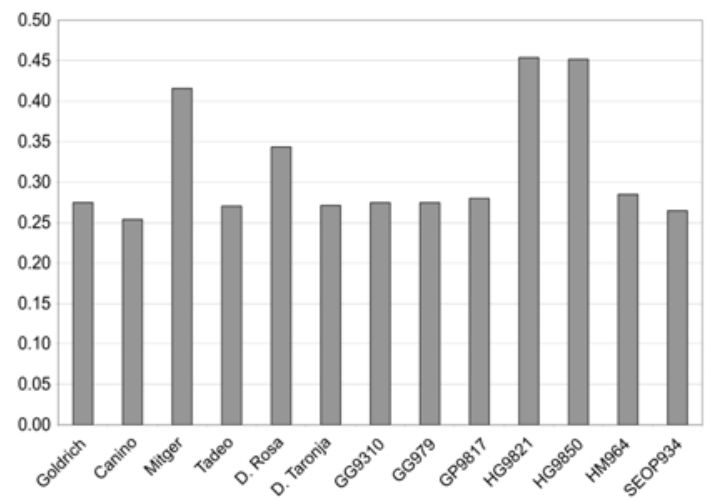

口Fumaric

Figure 3: Profiles of organic acids content in flesh (g/100 g FW) and peel (g /100 g DW) during 2016 and 2017. 
bioRxiv preprint doi: https://doi.org/10.1101/2020.11.30.403527: this version posted December 1.2020 . The copvriaht holder for this preprint (which was not certified by peer review) is the author/funder, who has granted bioRxiv a license to display the preprint in perpetuity. It is made available under aCC-BY-NC-ND 4.0 International license.

A

Flesh 2016 (mg/100 g FW)

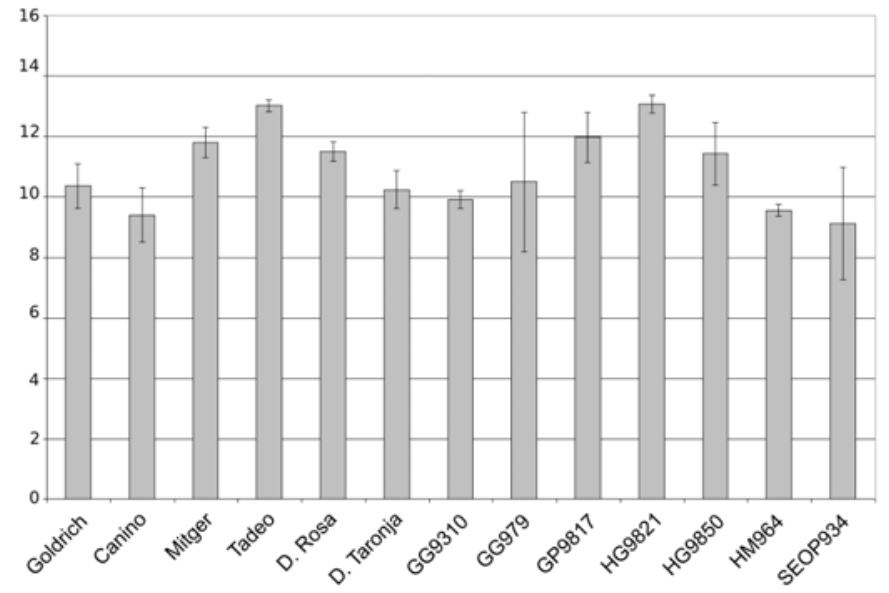

B

Peel 2016 (mg/100 g DW)

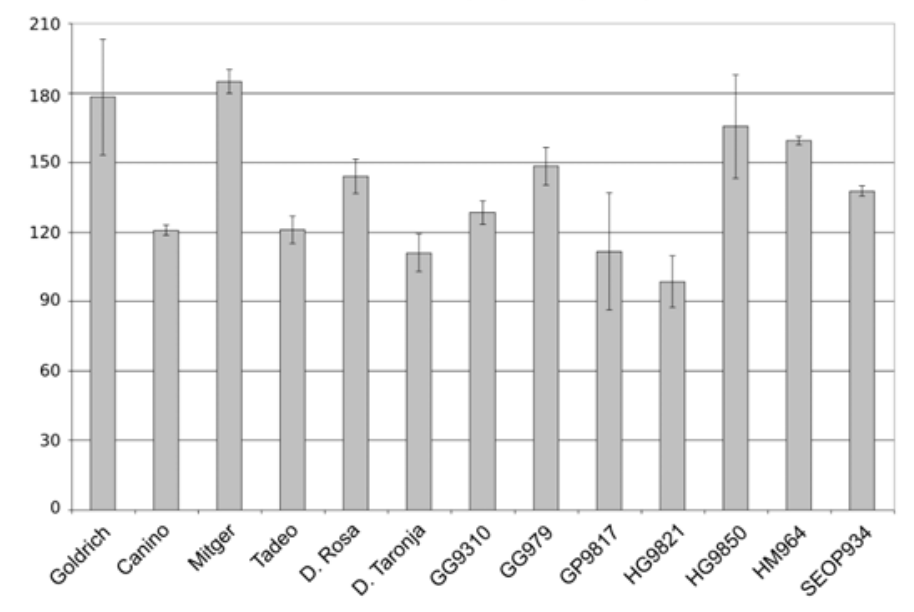

C

Peel 2017 (mg/100 g DW)

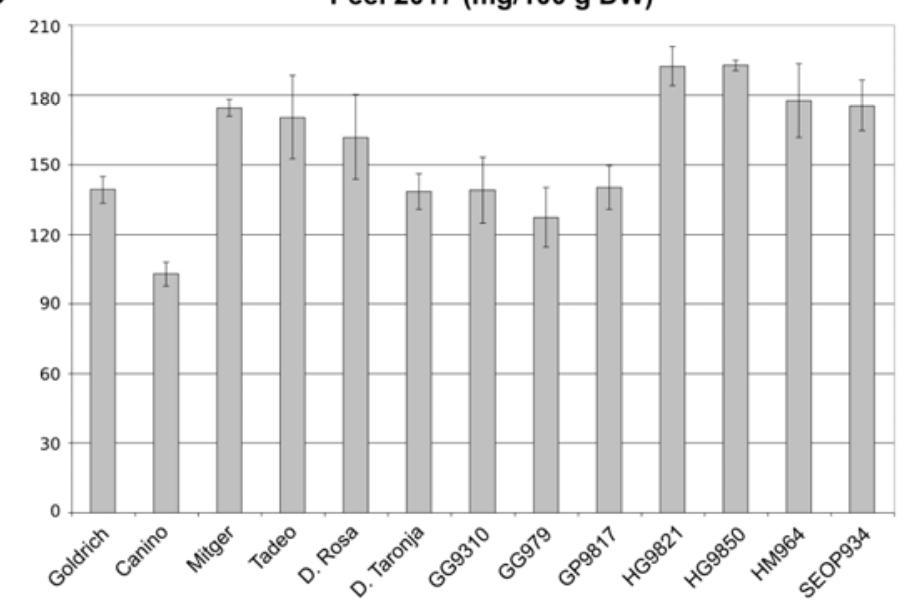

283 Figure 4: Ascorbic acid content in flesh (mg/100 g FW) and peel (mg /100 g DW) during 2016 and 2017. 

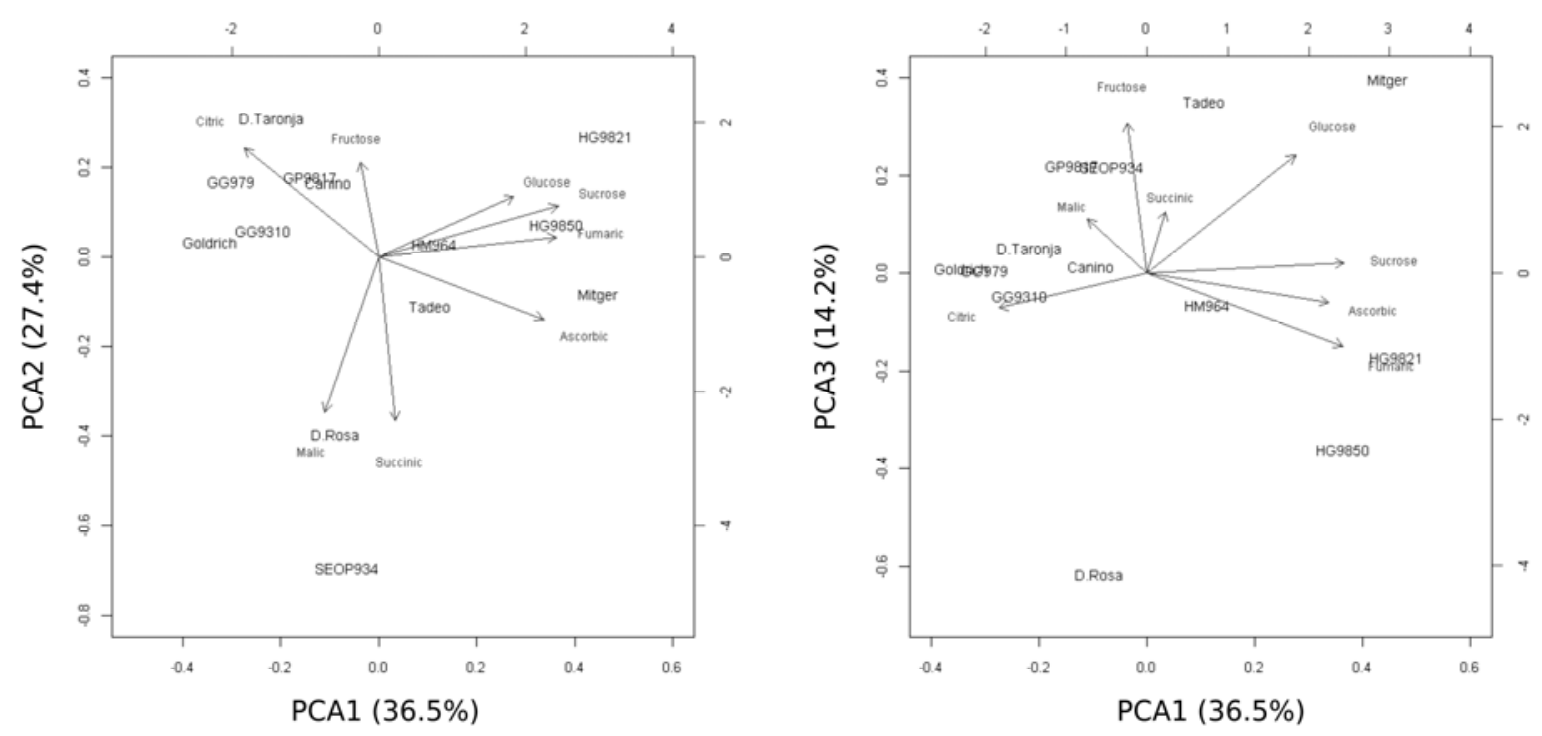

286 Figure 5: Principal Component Analysis for 2017 data. A: Representation of the accessions in the space defined

287 by the first and second components; B: Representation of the accessions in the space defined by the first and

288 third components.

290 Table S1: Profiles of sugar content in flesh (g/100 g fresh weight (FW)) and peel (g /100 g dry weight (DW))

291 during 2016 and 2017.

292 Table S2: Correlations between variables analysed.

293 Table S3: Profiles of organic acids content in flesh (g/100 g FW) and peel (g /100 g DW) during 2016 and 2017.

294 Table S4: Ascorbic acid content in flesh (mg/100 g FW) and peel (g /100 g DW) during 2016 and 2017.

295

296 References

297 Akin, E.B., Karabulut I., Topcu, A., 2008: Some compositional properties of main Malatya apricot (Prunus armeniaca

298 L.) varieties. Food Chemistry, 107, 939-948. DOI: 10.1016/j.foodchem.2007.08.052.

299 Azmir, J., Zaidul, I. S., Rahman, M.M., Sharif, K.M. Mohamed, A., Sahena, F., Jahurul, M.H.A., Ghafoor, K.

300 Norulaini, N.A.N., Omar, A.K.M., 2013: Techniques for extraction of bioactive compounds from plant materials: a

301 review. Journal of Food Engineering, 117, 426-436. DOI: 10.1016/j.jfoodeng.2013.01.014. 
302 Badenes, M.L., Martínez-Calvo, J., Gomez, H., Zuriaga, E., 2018: 'Dama Taronja' and 'Dama Rosa' apricot cultivars

303 that are resistant to sharka (plum pox virus). HortScience, 53, 1228-1229.

304 Bae, H. Yun, S.K. Jun, J.H. Yoon, I.K. Nam, E.Y., Kwon, J.H., 2014: Assessment of organic acid and sugar 305 composition in apricot, plumcot, plum, and peach during fruit development. Journal of Applied Botany and Food 306 Quality, 87, 24-29. DOI: 10.5073/JABFQ.2014.087.004.

307 Bassi, D., Selli, R., 1990: Evaluation of fruit quality in peach and apricot. Advances in Horticultural Science, 4, 107308112.

309 Campbell, O.E. Merwin, I.A., Padilla-Zakour, O.I., 2013: Characterization and the effect of maturity at harvest on the 310 phenolic and carotenoid content of Northeast USA apricot (Prunus armeniaca) varieties. Journal of Agricultural and 311 Food Chemistry, 61, 51, 12700-1271. DOI: 10.1021/jf403644r.

312 Cano, A. Bermejo, A., 2011: Rootstock and cultivar influence on bioactive compounds in citrus peels. Journal of the 313 Science of Food and Agriculture, 91, 1702-1711. https://onlinelibrary.wiley.com/doi/epdf/10.1002/jsfa.4375.

314 Cirilli, M., Bassi, D., Ciacciulli, A., 2016: Sugars in peach fruit: a breeding perspective. Horticulture Research, 3, 315 15067. DOI: 10.1038/hortres.2015.67.

316 D'Ambrosio, C., Arena S., Rocco, M., Verrillo, F., Novi, G., Viscosi, V. Marra, M., M. Sacloni, A., 2013: Proteomic 317 analysis of apricot fruit during ripening. Journal of Proteomics, 78, 39-57. https://doi.org/10.1016/j.jprot.2012.11.008.

318 Dolenc-Sturm, K., Stampar, F., Usenik, V., 1999: Evaluation of some quality parameters of different apricot cultivars 319 using HPLC method. Acta Alimentaria, 28, 297-309. DOI: 10.1556/AAlim.28.1999.4.1.

320 Fan, X., Zhao, H., Wang, X., Cao, J., Jiang, W., 2017: Sugar and organic acid composition of apricot and their 321 contribution to sensory quality and consumer satisfaction. Scientia Horticulturae, 225, 553-560. DOI: 322 10.1016/j.scienta.2017.07.016.

323 Fenech, M., Amaya, I., Valpuesta, V., Botella, M. A., 2019: Vitamin C Content in Fruits: Biosynthesis and Regulation. 324 Frontiers in plant science, 9, 2006. DOI: 10.3389/fpls.2018.02006.

325 Gündogdu, M., Kan, T., Gecer, M.K., 2013: Vitamins, flavonoids, and phenolic acid levels in early- and late-ripening 326 apricot (Prunus armeniaca L.) cultivars from Turkey. HortScience, 48, 696-700. DOI: 10.21273/HORTSCI.48.6.696.

327 Karlova, R., Chapman, N., Angenent, G.C., Seymour, G.B., de Maagd, R.A., 2014: Transcripcional control of fleshly 328 fruit development and ripening. Journal of Experimental Botany, 65, 4527-41. DOI: 10.1093/jxb/eru316. 
329 Kroger, M., Meister, K., Kava, R., 2006: Low-calorie sweeteners and other sugar substitutes: a review of the safety 330 issues. Comprehensive Reviews in Food Science and Food Safety, 5, 35-47. DOI: 10.1111/j.1541-4337.2006.tb00081.x.

331 Lee, S.K., Kader, A.A., 2000: Preharvest and postharvest factors influencing vitamin C content of horticultural crops.

332 Postharvest Biology and Technology, 20, 207-220. DOI: 10.1016/S0925-5214(00)00133-2.

333 Li, X., Wanf, T., Zhou, B., Gao, W., Cao, J., Huang, L., 2014: Chemical composition and antioxidant and anti334 inflammatory potential of peels and flesh from 10 different pear varieties (Pyrus spp.). Food Chemistry, 152, 531-538. 335 DOI: 10.1016/j.foodchem.2013.12.010.

336 Magwaza, L.S., Opara, U.L., 2015: Analytical methods for determination of sugars and sweetness of horticultural 337 products-A review. Scientia Horticulturae, 184, 179-192.

338 Martínez-Calvo, J., Font, A., Llácer, G. Badenes, M.L., 2009: Apricot And Peach Breeding Programs From The IVIA. 339 Acta Horticulturae, 814, 185-188. DOI: 10.17660/ActaHortic.2009.814.23.

340 Martínez-Gómez, P., Dicenta, F., Audergon, J.M., 2000: Behaviour of apricot (Prunus armeniaca L.) cultivars in the 341 presence of Sharka (Plum pox potyvirus): a review. Agronomie, 20, 407-22.

342 Moldes, A.B., Vecino, X., Cruz, J.M., 2017: Nutraceutical and food additives. In: Current development in 343 biotechnology (edited by C. Larroche, M. Sanroman, G. Du, A. Pandey). Pp. 143-164. Elsevier. ISBN: 978-0-444344 63666-9.

345 Moustafa, K., Cross, J., 2019: Production, pomological and nutraceutical properties of apricot. Journal of Food Science 346 and Technology, 56, 12-23. DOI: 10.1007/s13197-018-3481-7.

347 Osorio, S., Scossa, F., Fernie, A.R., 2013: Molecular regulation of fruit ripening. Frontiers in Plant Science, 4, 198. 348 DOI: 10.3389/fpls.2013.00198.

349 R Core Team, 2012: R: A language and environment for statistical computing. R Foundation for Statistical Computing, 350 Vienna, Austria. ISBN 3-900051-07-0. Retrieved November 11th 2020, from http://www.R-project.org/

351 Rice-Evans, C., Miller, N., Paganga, G., 1997: Antioxidant properties of phenolic compounds. Trends in Plant Science, 352 2, 152-159. DOI: 10.1016/S1360-1385(97)01018-2.

353 Ruiz D., Egea J., Gil M.I., Tomás-Barberán, F.A., 2005: Characterization and quantitation of phenolic compounds in 354 new apricot (Prunus armeniaca L.) varieties. Journal of Agricultural and Food Chemistry, 53, 9544-52. DOI: $35510.1021 / j f 051539 p$. 
356 Sajid, M., Khan, M.A., Bilal, W., Rab, A. Iqbal, Z., Khan, S.I., 2017: Anti-oxidant activities, chemical attributes and

357 fruit yield of peach cultivars as influenced by foliar application of ascorbic acid. Gesunde Pflanzen, 69, 113. DOI:

358 10.1007/s10343-017-0395-7.

359 Sdiri, S., Bermejo, A., Aleza, P., Navarro, P. Salvador, A., 2012: Phenolic composition, organic acids, sugars, vitamin

$360 \mathrm{C}$ and antioxidant activity in the juice of new triploid late-season mandarins. Food Research International, 49, $462-468$.

361 DOI:10.1016/j.foodres.2012.07.040.

362 Seymour G.B., Østergaard, L., Chapman, N.H., Knapp S., Martin C., 2013: Fruit development and ripening. Annual

363 Review of Plant Biology, 64, 219-241. DOI: 10.1146/annurev-arplant-050312-120057.

364 Slavin, J., Lloyd, B., 2012: Health benefits of fruits and vegetables. Advances in Nutrition, 3, 506-516. DOI: 365 10.3945/an.112.002154.

366 Sochor J, Zitka O, Skutkova H, Pavlik D, Babula P, Krska B, Horna A, Adam V, Provaznik I., Kizek, R., 2010: Content

367 of phenolic compounds and antioxidant capacity in fruits of apricot genotypes. Molecules, 15, 6285-6305. DOI: 368 10.3390/molecules15096285.

369 Tieman, D., Zhu, G., Resende, M.F. Jr, Lin, T., Nguyen, C., Bies, D., Rambla, J.L., Beltran, K.S., Taylor, M., Zhang,

370 B., Ikeda, H., Liu, Z., Fisher, J., Zemach, I., Monforte, A., Zamir, D., Granell, A., Kirst, M., Huang, S., Klee, H., 2017:

371 A chemical genetic roadmap to improved tomato flavor. Science, 355, 391-394. DOI:10.1126/science.aal1556.

372 Vieira da Silva, B., Barreira, J.CM., Oliveira, B.P.P., 2016: Natural phytochemicals and probiotics as bioactive

373 ingredients for functional foods: Extraction, biochemistry and protected-delivery technologies. Trends in Food Science

$374 \&$ Technology, 50, 144-155. DOI: 10.1016/j.tifs.2015.12.007.

375 Voo, S.S., Grimes, H.D., Lange, B.M., 2012: Assessing the biosynthetic capabilities of secretory glands in Citrus peel.

376 Plant Physiology, 159, 81-94. DOI: 10.1104/pp.112.194233.

377 Xi, W.P., Zheng, H. Zhang, Q., Wenhui, LI., 2016: Profiling taste and aroma compound metabolism during apricot fruit

378 development and ripening. International Journal of Molecular Science, 127, 998. DOI: 10.3390/ijms17070998.

379 Zhebentyayeva, T.N., Ledbetter, C., Burgos, L., Llácer, G., 2012: Apricots. In: Fruit Breeding (edited by M.L. Badenes 380 \& D.H. Byrne). Pp. 415-458. New York: Springer.

\section{ORCID:}

383 Helena Gómez-Martínez: https://orcid.org/0000-0001-8714-5197 
bioRxiv preprint doi: https://doi.org/10.1101/2020.1130.403527 this version posted December 1, 2020. The copyright holder for this preprint

(which was not certified by peer review) is the author/funder, who has granted bioRxiv a license to display the preprint in perpetuity. It is made available under aCC-BY-NC-ND 4.0 International license.

384 Almudena Bermejo: https://orcid.org/0000-0003-4030-6007

385 María Luisa Badenes: https://orcid.org/0000-0001-9722-6783

386 Elena Zuriaga*: https://orcid.org/0000-0001-5497-4941

$387 *$ Corresponding author: garcia_zur@gva.es

388 Postal address:

389 Citriculture and Crop Production Center, Instituto Valenciano de Investigaciones Agrarias (IVIA), CV-315, Km. 10.7,

390 Moncada, 46113 Valencia, Spain

391 